Review began 11/15/2021 Review ended 11/25/2021 Published 11/27/2021

(c) Copyright 2021

Nhi et al. This is an open access article distributed under the terms of the Creative Commons Attribution License CC-BY 4.0. which permits unrestricted use, distribution, and reproduction in any medium, provided the original author and source are credited.

\section{Role of Dual-Energy Computed Tomography in the Identification of Monosodium Urate Deposition in Gout Patients: A Comprehensive Analysis of 828 Joints According to Structural Joint Damage}

Le Huu Hanh Nhi ${ }^{1}$, Le Huu Nhat Minh ${ }^{2}$, Thuan Minh Tieu ${ }^{3}$, Esraa Mahmoud Mostafa ${ }^{4}$, Sedighe Karimzadeh ${ }^{5}$, Nguyen Minh Dung ${ }^{6}$, Nguyen Hai Nam ${ }^{7}$, Le Van Phuoc ${ }^{8}$, Nguyen Tien Huy ${ }^{9}$

1. Department of Radiology, Vinmec Healthcare System, Ho Chi Minh City, VNM 2. Faculty of Medicine, University of Medicine and Pharmacy at Ho Chi Minh City, Ho Chi Minh City, VNM 3. Department of Medicine, McMaster University, Hamilton, CAN 4. Department of Medicine, Port Said University, Port Said, EGY 5. Online Research Club, School of Tropical Medicine and Global Health, Nagasaki University, Nagasaki, JPN 6. Department of Medicine, Vietnam National University, Ho Chi Minh City, VNM 7. Department of Surgery, Kyoto University, Kyoto, JPN 8. Department of Radiology, Cho Ray Hospital, Ho Chi Minh City, VNM 9. School of Tropical Medicine and Global Health, Nagasaki University, Nagasaki, JPN

Corresponding author: Le Huu Nhat Minh, lehuunhatminh@gmail.com

\section{Abstract}

\section{Background}

Dual-energy computed tomography (DECT) has become a promising, non-invasive procedure for the visualization, characterization, and quantification of monosodium urate (MSU) crystals, which aids clinicians in the diagnosis of gout. In this study, we aimed to examine the diagnostic accuracy of DECT in the evaluation of gout.

\section{Methodology}

This cross-sectional retrospective study included patients who were clinically diagnosed with gout and underwent a DECT scan.

\section{Results}

A majority (80.4\%) of the MSU deposits were found in the ankle joints. The presence of MSU deposits on DECT scan was highly correlated with bone erosion in the upper limb (odds ratio $[\mathrm{OR}]=132$; $95 \%$ confidence interval $[\mathrm{CI}]=17.3-1004.3)$, bone sclerosis in the lower limb $(\mathrm{OR}=36.4$; 95\% CI $=15.4-86.1)$, bone erosion in metacarpophalangeal joints $(\mathrm{OR}=160 ; 95 \% \mathrm{CI}=42.7-600.2)$, and bone sclerosis in metatarsophalangeal joints $(\mathrm{OR}=35.6 ; 95 \% \mathrm{CI}=15.5-81.9)$. Using linear regression analysis on patient-level data, correlations were found between DECT MSU crystal deposition and damage on all categories of structural joint damage showing significant association with erosion $(r=0.91, p<0.001)$ and space narrowing $(r=0.75, p<0.001)$ but not with joints having periarticular calcification $(\mathrm{r}=0.52, \mathrm{p}<0.041)$.

\section{Conclusions}

Our study established DECT as a valid method for detecting MSU deposits and their association with structural joint deterioration in a Vietnamese population.

Categories: Radiology, Rheumatology

Keywords: monosodium urate deposition, urate, dect, dual-energy computed tomography, gout, radiography, musculoskeletal imaging

\section{Introduction}

Gout is a common form of inflammatory arthritis that is characterized by elevated serum uric acid and deposition of monosodium urate (MSU) crystals in the joints and soft tissue [1]. The long-term clinical consequences of MSU deposition in joints are tophi, which can present in acute or chronic forms. In its acute form, gouty arthritis is characterized by sudden-onset intense and recurring pain [2]. Hence, the urgent detection of MSU is crucial for diagnosis and management. Microscopic analysis of synovial fluid looking for needle-shaped MSU crystals by arthrocentesis is the gold standard tool for the diagnosis of gout [3]. Other medical conditions such as rheumatoid arthritis, osteoarthritis, infectious arthritis, or calcium pyrophosphate deposition share similar clinical presentations as gout. While serum uric acid concentration and medical imaging such as X-ray and ultrasound assist in the diagnosis, the gold standard for establishing 
a definite diagnosis of gout is the presence of MSU in aspirated joint fluid [4]. Several diagnostic methods have been developed for gout diagnosis. The clinical features of gout such as intense pain with tenderness may be absent in some patients, some patients may show a normal serum uric acid level, and sometimes uric acid crystals cannot be detected using the standard methods. In these circumstances when a definite diagnosis cannot be established, imaging modality can help in the identification of affected joints and their burden.

Imaging modalities such as ultrasonography (US), magnetic resonance imaging (MRI), conventional computed tomography (CT), and dual-energy computed tomography (DECT) can help in the identification of clinical and intra-articular tophi [5]. DECT scan has been suggested for the diagnosis of gout in the 2015 Gout Classification Criteria, an American College of Rheumatology/European League Against Rheumatism Collaborative Initiative. DECT is a non-invasive test with high sensitivity and specificity to detect MSU crystals in affected joints, tendons, ligamentous, and involved tissues [5]. The technique helps detect smallsized crystals in uncommon areas before clinical manifestation, assisting clinicians in the diagnosis as well as treatment. On the other hand, arthrocentesis, or joint aspiration, is an invasive procedure and can be difficult to perform on an acute inflammatory small joint; moreover, it carries the risk of bleeding, infection, or damage to nearby structures [6]. DECT can detect four times more tophi than clinical examination alone $[7]$.

Although many studies have been conducted worldwide [8-10] using DECT for the diagnosis of gout, it is not commonly performed in Vietnam. Although a few centers are capable of performing this technique, it is not widely employed to date and no publications exist. Therefore, we conducted this study to evaluate a new technique for diagnosing gout in clinical practice.

\section{Materials And Methods Study population}

A cross-sectional study was performed on 36 patients diagnosed with gout at Cho Ray Hospital, Ho Chi Minh City, Vietnam from March 2017 to May 2018. All patients were diagnosed with gout using clinical findings, serum uric acid testing, and imaging methods with scores $>8$ based on the American College of Rheumatology/European League Against Rheumatism 2015 guidelines. Patients who underwent DECT in the lower and upper extremities were included. Patients whose imaging had technical errors when DECT was employed or those who had artifacts in DECT imaging were excluded. Because only recorded findings and stored images were collected, there was no interference with patients' or clinicians' treatment decisions. The personal information of the patients involved in the study was confidential. The study was approved by the Ethics Research Council of the University of Medicine and Pharmacy at Ho Chi Minh City, Vietnam.

\section{Study protocol}

Clinical assessment, classification, and DECT scanning were performed from March 2017 to May 2018 for patients diagnosed with gout. Collected data included demographic characteristics, MSU crystal deposition, and blood uric acid findings of patients based on medical records (inpatient and outpatient).

\section{Dual-energy computed tomography protocol}

DECT scanning was performed using SOMATOM Definition Edge (Siemens Medical, Erlangen, Germany) with a filter in front of the tube and no contrast injections. The scanning position was the patient lying on the back with arms facing towards the head. The scanning area was from above the elbow joint at least $5 \mathrm{~cm}$ to the end of the finger and from above the knee joint at least $5 \mathrm{~cm}$ to the end of the toes. The scanner started shooting at $120 \mathrm{kVp}$, and then two sets of data were developed using a gold filter plate with a low energy spectrum $(80 \mathrm{kVp})$ and tin with a high energy spectrum $(140 \mathrm{kVp})$. Based on the calculations of threedimensional images and predetermined thresholds, sodium urate crystals and bone were color-coded for easier visualization and volume calculation. Two-dimensional and three-dimensional color maps were recorded and integrated with corresponding CT images to simultaneously display the anatomical structure and urate crystal deposition location. The imaging features of structural joint damage that were recorded included MSU deposition, bone erosion, periarticular calcification, joint space narrowing, and bone sclerosis. After collection, data were transferred into the Syngovia system. The DECT images of patients were processed and three-dimensionally rendered by supporting software.

\section{Statistical analysis}

Data were input into Microsoft Excel and analyzed using SPPS version 22.0 (IBM Corp., Armonk, NY, USA). Categorical variables were presented as proportions while the median (range) or mean (standard deviation) were used to summarize continuous variables, which included the clinical and imaging characteristics of our samples. Pearson's correlation tests were used to investigate correlations between variables. Linear regression models were used to examine the relationship between DECT MSU crystal deposition and serum urate concentration on joint damage. The tests were considered statistically significant at p-values of $<0.05$. The correlation coefficient $(r)$ and standardized beta $(\beta)$ were defined as follows: -1 indicates a strong negative correlation, 0 indicates no association, and +1 indicates a strong positive correlation. 


\section{Cureus}

\section{Results}

\section{Patient characteristics}

The DECT results of 23 patients were selected for analysis in this study (Figure 1). All participants were males, with the mean age and standard deviation of 55.3 and 13.8 years. The median (interquartile range) disease duration was 7.5 (4-10) years. Subcutaneous tophus was noted in 20 (87\%) patients. There were 14 (61\%) patients with gout disease for more than three years. The mean and standard deviation of serum uric acid level was 8.3 and $1.7 \mathrm{mg} / \mathrm{dL}$, respectively. Further, among these patients, the median (interquartile range) volume of overall urate deposition was $8.88(1.18-15.40) \mathrm{cm}^{3}$.
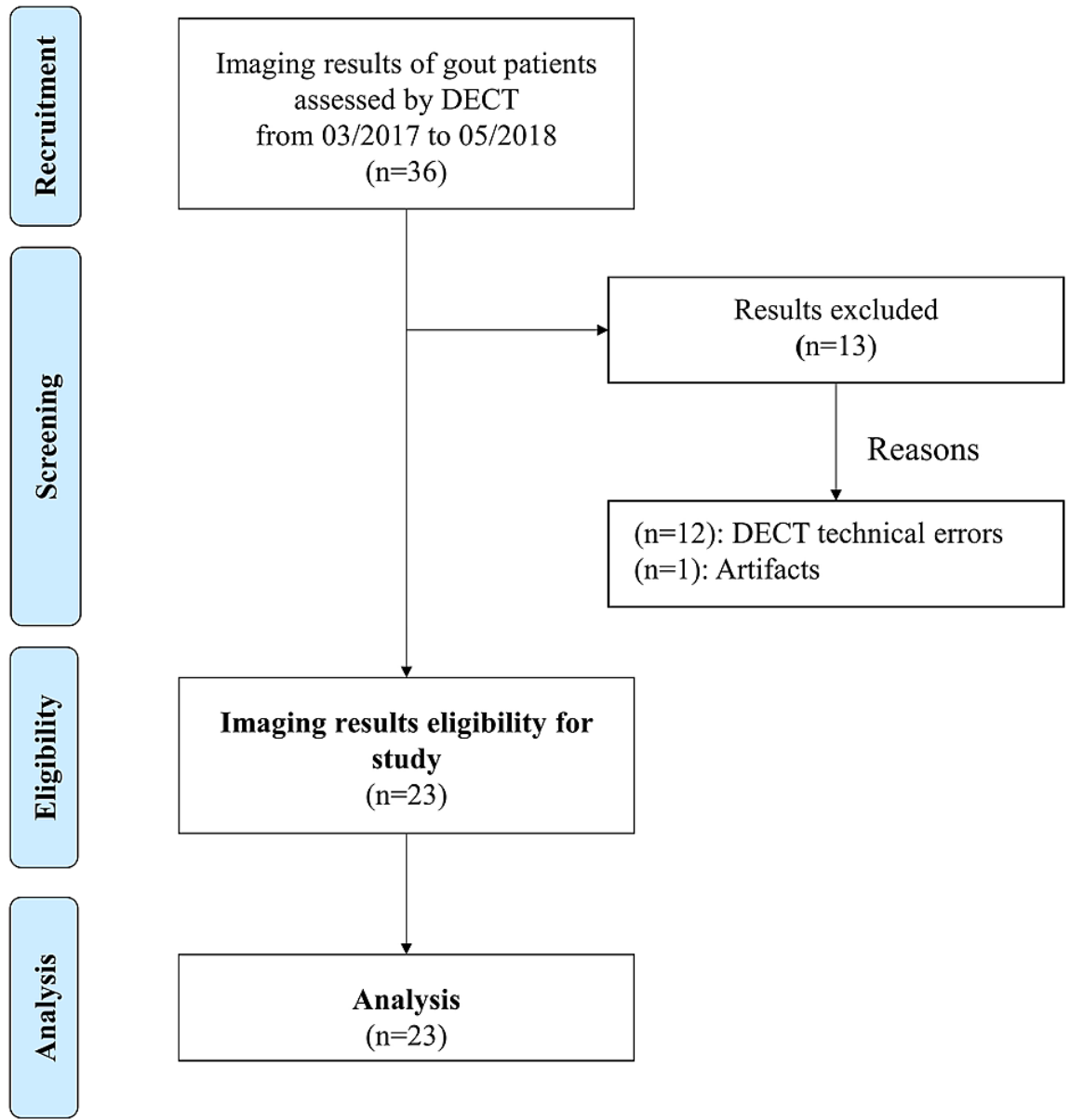

FIGURE 1: Flow diagram of patient enrollment.

DECT: dual-energy computed tomography

\section{Clinical characteristics}

Regarding the distribution of tophi volume, $75 \%$ of the patients had a total tophi volume of approximately $10.5 \mathrm{~cm}^{3}$ or lower and approximately $6 \mathrm{~cm}^{3}$ or lower in the lower and upper extremities, respectively. Overall, $75 \%$ of the patients had the maximum tophi volume of $2.3 \mathrm{~cm}^{3}$ in the lower extremities and approximately $1 \mathrm{~cm}^{3}$ or lower in the upper extremities (Figure 2). 


\section{Cureus}

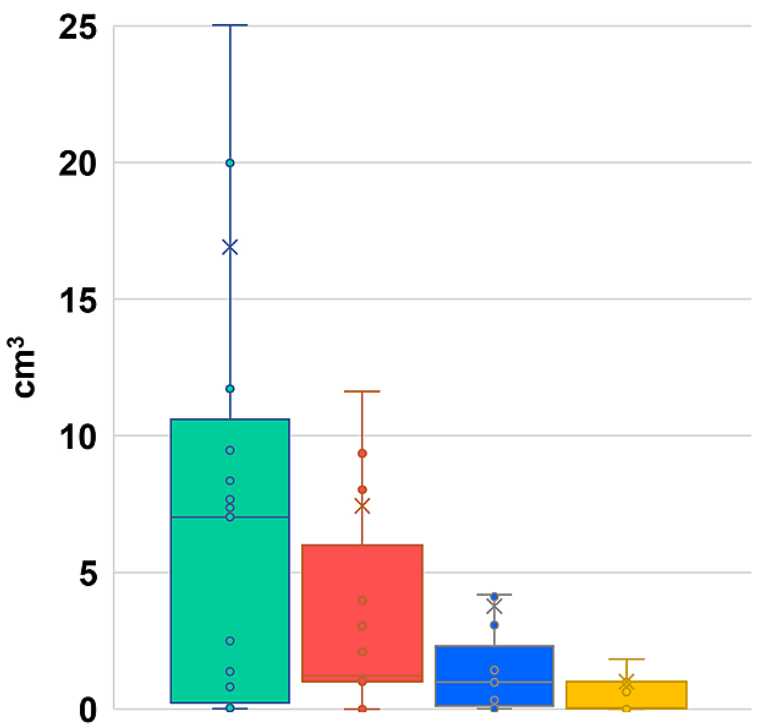

$\square$ Total tophus volume of lower extremities

Total tophus volume of upper extremities

Maximum tophus volume of lower extremities

Maximum tophus volume of upper extremities

FIGURE 2: Distribution of tophi volume by extremity.

The distribution according to the general area affected in the lower and upper extremities is shown in Table 1. There were 104 (56.5\%; $95 \%$ confidence interval $[\mathrm{CI}]=49.3 \%-63.7 \%)$ and $63(34.2 \%$; $95 \% \mathrm{CI}=27.4 \%$ $41.1 \%$ ) joints with DECT urate deposition in lower and upper limbs, respectively. Sclerosis was the most commonly observed structural joint damage, with 113 joints $(61.4 \%$; $95 \% \mathrm{CI}=54.4 \%-68.5 \%)$ in the lower limbs and 44 joints $(23.9 \%$; $95 \% \mathrm{CI}=17.7 \%-30.1 \%)$ in the upper limbs. In comparison, space narrowing was the least observed feature, with 59 (32.1\%; $95 \% \mathrm{CI}=25.3 \%$-38.8\%) and 28 (15.2\%; 95\% CI = 10\%-20.4\%) joints in lower and upper limbs, respectively. 


\section{Cureus}

\begin{tabular}{|c|c|c|c|c|c|}
\hline Imaging feature & $\begin{array}{l}\text { Monosodium urate } \\
\text { crystals, } \%(95 \% \mathrm{Cl})\end{array}$ & $\begin{array}{l}\text { Bone erosion, } \\
\%(95 \% \mathrm{Cl})\end{array}$ & $\begin{array}{l}\text { Periarticular } \\
\text { calcification, \% (95\% } \\
\text { Cl) }\end{array}$ & $\begin{array}{l}\text { Joint space } \\
\text { narrowing, \% (95\% } \\
\text { Cl) }\end{array}$ & $\begin{array}{l}\text { Bone sclerosis, } \\
\%(95 \% \mathrm{Cl})\end{array}$ \\
\hline \multicolumn{6}{|l|}{ Lower extremities $(n=46)$} \\
\hline Knee & 71.7\% (58.6-84.9) & $\begin{array}{l}32.6 \%(18.9- \\
46.3)\end{array}$ & $63 \%(48.9-77.1)$ & $37 \%(22.9-51.1)$ & $\begin{array}{l}84.8 \%(74.3- \\
95.3)\end{array}$ \\
\hline Ankle joints & $80.4 \%(68.8-92)$ & $43.5 \%(29-58)$ & $69.6 \%(56.1-83)$ & $28.3 \%(15.1-41.4)$ & $\begin{array}{l}78.3 \%(66.2- \\
90.3)\end{array}$ \\
\hline $\begin{array}{l}\text { Metatarsophalangeal } \\
\text { joints }\end{array}$ & $45.7 \%(31.1-60.2)$ & $\begin{array}{l}47.8 \%(33.2- \\
62.4)\end{array}$ & $45.7 \%(31.1-60.2)$ & $34.8 \%(20.9-48.7)$ & $\begin{array}{l}47.8 \%(33.2- \\
62.4)\end{array}$ \\
\hline Interphalangeal joint & $28.3 \%(15.1-41.4)$ & $\begin{array}{l}32.6 \%(18.9- \\
46.3)\end{array}$ & 28.3\% (15.1-41.4) & $28.3 \%(15.1-41.4)$ & $\begin{array}{l}34.8 \%(20.9- \\
48.7)\end{array}$ \\
\hline Total affected joints & $56.5 \%(49.3-63.7)$ & $\begin{array}{l}39.1 \%(25- \\
53.3)\end{array}$ & $51.6 \%(44.4-58.9)$ & $32.1 \%(25.3-38.8)$ & $\begin{array}{l}61.4 \%(54.4- \\
68.5)\end{array}$ \\
\hline $\begin{array}{l}\text { Patients affected lower } \\
\text { extremities (\%) }\end{array}$ & 100 & 52.2 & 82.6 & 56.5 & 91.3 \\
\hline \multicolumn{6}{|l|}{ Upper extremities ( $n=46$ ) } \\
\hline Elbow & $58.7 \%(44.3-73.1)$ & $\begin{array}{l}21.7 \%(9.7- \\
33.8)\end{array}$ & $28.3 \%(15.1-41.4)$ & $17.4 \%(6.3-28.5)$ & $17.4 \%(6.3-28.5)$ \\
\hline Carpometacarpal joint & $34.8 \%(20.9-48.7)$ & $19.6 \%(8-31.2)$ & $21.7 \%(9.7-33.8)$ & $17.4 \%(6.3-28.5)$ & $\begin{array}{l}45.7 \%(31.1- \\
60.2)\end{array}$ \\
\hline $\begin{array}{l}\text { Metacarpophalangeal } \\
\text { joint }\end{array}$ & $23.9 \%(11.5-36.4)$ & $\begin{array}{l}23.9 \%(11.5- \\
36.4)\end{array}$ & $19.6 \%(8-31.2)$ & $15.2 \%(4.7-25.7)$ & $21.7 \%(9.7-33.8)$ \\
\hline Interphalangeal joint & $19.6 \%(8-31.2)$ & $8.7 \%(0.5-16.9)$ & $10.9 \%(1.8-20)$ & $10.9 \%(1.8-20)$ & $10.9 \%(1.8-20)$ \\
\hline Total affected joints & $34.2 \%(27.4-411)$ & $\begin{array}{l}18.5 \%(12.9- \\
24,1)\end{array}$ & $20.1 \%(14.3-25.9)$ & $15.2 \%(10-20.4)$ & $\begin{array}{l}23.9 \%(17.7- \\
30.1)\end{array}$ \\
\hline $\begin{array}{l}\text { Patients affected in } \\
\text { upper extremities (\%) }\end{array}$ & 82.6 & 26.1 & 52.2 & 26.1 & 21.7 \\
\hline
\end{tabular}

TABLE 1: Distribution according to the general area affected in lower and upper extremities.

Cl: confidence interval

A total of 828 joint sites were assessed to determine the relationship of MSU deposition in DECT with structural joint damage on plain CT. The sites are divided into the following four areas: upper limb, lower limb, metacarpophalangeal (MCP), and metatarsophalangeal (MTP) (Table 2). 


\section{Cureus}

\begin{tabular}{|c|c|c|c|c|c|c|c|}
\hline $\begin{array}{l}\text { Erosion } \\
\text { present }\end{array}$ & $\begin{array}{l}\text { Erosion } \\
\text { absent }\end{array}$ & $\begin{array}{l}\text { Periarticular } \\
\text { calcification } \\
\text { present }\end{array}$ & $\begin{array}{l}\text { Periarticular } \\
\text { calcification } \\
\text { absent }\end{array}$ & $\begin{array}{l}\text { Joint space } \\
\text { narrowing } \\
\text { present }\end{array}$ & $\begin{array}{l}\text { Joint space } \\
\text { narrowing } \\
\text { absent }\end{array}$ & $\begin{array}{l}\text { Bone } \\
\text { sclerosis } \\
\text { present }\end{array}$ & $\begin{array}{l}\text { Bone } \\
\text { sclerosis } \\
\text { absent }\end{array}$ \\
\hline \multicolumn{8}{|c|}{ Upper extremities $(n=184)$} \\
\hline 33 & 30 & 34 & 29 & 28 & 35 & 37 & 26 \\
\hline 1 & 120 & 3 & 118 & 0 & 121 & 7 & 114 \\
\hline $132(17.3$ & $-1004.3)^{\#}$ & $46.1(13.2-160.7)^{\#}$ & & NA & & $23.2(9.3-5$ & \\
\hline \multicolumn{8}{|c|}{ Lower extremities $(n=184)$} \\
\hline 65 & 39 & 80 & 24 & 53 & 51 & 95 & 9 \\
\hline 7 & 73 & 15 & 65 & 6 & 74 & 18 & 62 \\
\hline $17.4(7.3-$ & 41.5) & $14.4(7-29.8)^{\#}$ & & $12.8(5.1-32)^{\#}$ & & $36.4(15.4-$ & \\
\hline \multicolumn{8}{|c|}{ Metacarpophalangeal $(n=230)$} \\
\hline 20 & 5 & 20 & 5 & 15 & 10 & 22 & 3 \\
\hline 5 & 200 & 8 & 197 & 0 & 205 & 11 & 194 \\
\hline $160(42.7$ & $-600.2)^{\#}$ & $98.5(29.4-329.8)^{\#}$ & & NA & & $129.3(33.5$ & \\
\hline \multicolumn{8}{|c|}{ Metatarsophalangeal $(n=230)$} \\
\hline 62 & 16 & 41 & 37 & 40 & 38 & 70 & 8 \\
\hline 16 & 136 & 20 & 132 & 9 & 143 & 30 & 122 \\
\hline \multicolumn{2}{|c|}{$32.9(15.5-70.1)^{\#}$} & \multicolumn{2}{|l|}{$7.3(3.8-14.0)^{\#}$} & \multicolumn{2}{|l|}{$16.7(7.5-37.5)^{\#}$} & \multicolumn{2}{|c|}{$35.6(15.5-81.9)^{\#}$} \\
\hline
\end{tabular}

TABLE 2: Relationship of DECT MSU crystal deposition with structural joint damage on plain CT: site-by-site analysis according to the general area.

\#logistic regression was used to calculate odds ratios and $95 \%$ confidence intervals.

CD: crystal deposition; DECT: dual-energy computed tomography; MSU: monosodium urate; CT: computed tomography

Upper Limb Joint Sites

In total, 184 joint sites showed MSU deposition on DECT. In DECT findings, MSU deposition sites associated with bone erosion and periarticular calcification were statistically significantly correlated with sites that did not have MSU deposition (odds ratio $[\mathrm{OR}]=132 ; 95 \% \mathrm{CI}=17.3-1004.3$, and $\mathrm{OR}=46.1$; 95\% CI = 13.2-160.7, respectively; $\mathrm{p}<0.001$ ). Additionally, bone sclerosis had a statistically significant relationship with DECT ( $p$ $<0.001)$ but did not vary considerably $(\mathrm{OR}=23.2 ; 95 \% \mathrm{CI}=9.3-57.8)$ (Table 2$)$.

Lower Limb Joint Sites

The number of sites was the same as the upper limb ( $n=184$ sites). As expected, MSU deposition sites on DECT were significantly associated with a greater risk of bone sclerosis, bone erosion, periarticular calcification, and joint space narrowing compared with missing MSU deposition sites $(\mathrm{OR}=36.4$, 95\% CI = $15.4-86.1 ; \mathrm{OR}=17.4,95 \% \mathrm{CI}=7.3-41.5 ; \mathrm{OR}=14.4,95 \% \mathrm{CI}=7.0-29.8 ; \mathrm{OR}=12.8,95 \% \mathrm{CI}=5.1-32$, respectively; $\mathrm{p}<0.001$ ) in a descending order (Table 2).

Metacarpophalangeal Joint Sites

In 230 sites tested by DECT, compared with absent MSU deposition sites, sites with MSU deposition were as likely to have joint injury in the following three features: bone erosion $(\mathrm{OR}=160 ; 95 \% \mathrm{CI}=42.7-600.2)$, bone sclerosis $(\mathrm{OR}=129.3$; 95\% CI $=33.5-499)$, and periarticular calcification $(\mathrm{OR}=98.5 ; 95 \% \mathrm{CI}=29.4-329.8)(\mathrm{p}<$ 0.001) (Table 2). 


\section{Cureus}

Similarly, 230 MTP sites assessed by DECT also highlighted the relationship between MSU deposition sites and joint injuries on plain CT. MSU deposition sites on DECT showed an increased risk of bone sclerosis, bone erosion, and periarticular calcification compared with absent MSU deposition sites ( $\mathrm{OR}=35.6,95 \% \mathrm{CI}=$ 15.5-81.9; $\mathrm{OR}=32.9,95 \% \mathrm{CI}=15.5-70.1 ; \mathrm{OR}=7.3,95 \% \mathrm{CI}=3.8-14$, respectively; $\mathrm{p}<0.001$ ) (Table 2). Using linear regression analysis on patient-level data, significant correlations were found between DECT MSU crystal deposition and damage on all categories of structural joint damage $(\mathrm{p}<0.05$ for erosion, calcification, space narrowing) but not sclerosis $(\mathrm{p}=0.29)$.

The opposite finding was noted in the case of serum urate concentration $(\mathrm{mg} / \mathrm{dL})$, which had no statistically significant relationship with any features of structural joint damage ( $p>0.05$ for all categories). Positive correlations were observed between DECT MSU crystal deposition and serum urate concentration regarding erosion, calcification, and space narrowing of the joint ( $\mathrm{p}<0.001, \mathrm{p}<0.041, \mathrm{p}<0.001$, respectively). However, no statistically significant relationship was noted between these two predictors in sclerosis $(\mathrm{p}<$ 0.12 ) (Table 3). A strong linear relationship was observed in the frequency of MSU crystal deposition with erosion.

\begin{tabular}{|c|c|c|c|c|c|}
\hline Dependent variable & Predictors & $\beta(\mathrm{SE})$ & $\begin{array}{l}\text { Standardized } \\
\beta\end{array}$ & $\begin{array}{l}\mathrm{P}- \\
\text { value }\end{array}$ & Model (r, $R^{2}, F, p$-value) \\
\hline \multirow{2}{*}{ Number of joints with erosion } & $\begin{array}{l}\text { Number of joints with DECT MSU } \\
\text { crystal deposition }\end{array}$ & $\begin{array}{l}0.99 \\
(0.1)\end{array}$ & 0.92 & $<0.001$ & \multirow{2}{*}{$\begin{array}{l}r=0.91, R^{2}=0.83, F= \\
48.4, p<0.001\end{array}$} \\
\hline & Serum urate concentration $(\mathrm{mg} / \mathrm{dL})$ & $\begin{array}{l}-0.09 \\
(0.22)\end{array}$ & -0.04 & 0.7 & \\
\hline \multirow{2}{*}{$\begin{array}{l}\text { Number of joints with periarticular } \\
\text { calcification }\end{array}$} & $\begin{array}{l}\text { Number of joints with DECT MSU } \\
\text { crystal deposition }\end{array}$ & $\begin{array}{l}0.48 \\
(0.18)\end{array}$ & 0.53 & 0.01 & \multirow{2}{*}{$\begin{array}{l}r=0.52, R^{2}=0.27, F= \\
3.8, p<0.041\end{array}$} \\
\hline & Serum urate concentration $(\mathrm{mg} / \mathrm{dL})$ & $\begin{array}{l}-0.09 \\
(0.38)\end{array}$ & -0.05 & 0.81 & \\
\hline \multirow{2}{*}{$\begin{array}{l}\text { Number of joints with joint space } \\
\text { narrowing }\end{array}$} & $\begin{array}{l}\text { Number of joints with DECT MSU } \\
\text { crystal deposition }\end{array}$ & $\begin{array}{l}0.67 \\
(0.14)\end{array}$ & 0.76 & $<0.001$ & \multirow{2}{*}{$\begin{array}{l}r=0.75, R^{2}=0.56, F= \\
12.6, p<0.001\end{array}$} \\
\hline & Serum urate concentration $(\mathrm{mg} / \mathrm{dL})$ & $\begin{array}{l}-0.12 \\
(0.29)\end{array}$ & -0.07 & 0.67 & \\
\hline Number of joints with sclerosis & $\begin{array}{l}\text { Number of joints with DECT MSU } \\
\text { crystal deposition }\end{array}$ & $\begin{array}{l}0.29 \\
(0.27)\end{array}$ & 0.22 & 0.29 & $\begin{array}{l}r=0.44, R^{2}=0.19, F= \\
2.4, p<0.12\end{array}$ \\
\hline \multicolumn{6}{|c|}{$\begin{array}{l}\text { TABLE 3: Linear regression analysis showing the relationships between DECT MSU crystal } \\
\text { deposition and serum urate with structural joint damage on plain CT: patient-level analysis ( } n= \\
\text { 23). }\end{array}$} \\
\hline \multicolumn{6}{|c|}{ DECT: dual-energy computed tomography; MSU: monosodium urate } \\
\hline
\end{tabular}

\section{Discussion}

From March 2017 to May 2018, we enrolled 23 eligible patients in this study. MSU deposits were mostly found in the ankle joints. The presence of MSU deposits detected on the DECT scan was highly correlated with bone erosion in the upper limb and MCP joints and with bone sclerosis in the lower limb and MTP joints. All included patients were males, which is expected as gout is predominantly seen in males [11]. In addition, we excluded female participants with gout. Hence, in our study, the male-to-female ratio is higher than that reported in other similar studies [12-14]. The mean age in our study was $55 \pm 14$ years, ranging from 37 to 88 years. The mean age reported by Choi et al. (2012) [12], Mallinson et al. (2013) [13], and Dalbeth et al. (2014) [14] was 62, 61.3, and 58, respectively. According to the literature, gout is not common in patients under the age of 45 , but $26.1 \%(n=6 / 23)$ of our participants were under the age of 45 . This suggests an increasing incidence of gout in the younger population. Hyperuricemia occurs when the serum uric acid level is over $7 \mathrm{mg} / \mathrm{dL}$ in males and $6 \mathrm{mg} / \mathrm{dL}$ in females. The condition can be caused by increased production of uric acid, a decrease in the renal secretion of uric acid, or a combination of these causes. The mean serum uric acid level in our study was $8.3 \pm 1.7 \mathrm{mg} / \mathrm{dL}$, which is higher than similar studies by Choi et al. [12] (6.3 mg/dL) and Dalbeth et al. [14] (7.2 and 2.0) $\mathrm{mg} / \mathrm{dL})$. Of these, $91.3 \%(n=21 / 23)$ of our participants had serum uric acid levels above $6 \mathrm{mg} / \mathrm{dL}$, which is significantly higher compared to other studies. Hyperuricemia is an important risk factor for incident gout [15]. However, Schlesinger et al. [16] found no correlation between the incidence of gout and serum uric acid level. Of 339 patients, one-third with acute gout had a serum uric acid level lower than $8 \mathrm{mg} / \mathrm{dL}$ [16]. In another study, the risk of gout 


\section{Cureus}

increased from $0.33 \%$ in patients with serum uric acid levels less than $6 \mathrm{mg} / \mathrm{dL}$ to $26 \%$ in patients with serum uric acid levels more than $10 \mathrm{mg} / \mathrm{dL}$ in five years. The 15 -year cumulative incidence ranged from $1.1 \%$ for $<6$ $\mathrm{mg} / \mathrm{dL}$ to $49 \%$ for $>10 \mathrm{mg} / \mathrm{dL}$ [17]. On one hand, we found MSU crystal disposition in asymptomatic joints in patients with hyperuricemia. On the other hand, there were cases where even though hyperuricemia was confirmed and the joints showed clinical symptoms, MSU crystal disposition was not found on the DECT scan. Therefore, maintaining normal serum uric acid levels is the goal in gout management. A serum uric acid level below $6 \mathrm{mg} / \mathrm{dL}$ helps dissolve MSU crystals, thus reducing the clinical symptoms [18,19].

In this study, 87\% (20/23) of the patients presented with clear clinical symptoms. We observed MSU crystal depositions more frequently and with a larger volume in gout patients with more obvious symptoms. In addition, there were cases where MSU crystal depositions were detected in asymptomatic patients with low serum uric acid levels. This can be explained by the large number of participants who were on medications for hyperuricemia in this study (70\%). However, this percentage is lower than that reported in other similar studies: Choi et al. [12] (87\%) and Dalbeth et al. [14] (92\%). In addition, 60.9\% (14/23) of the participants had chronic gout for more than three years, with higher MSU crystal deposition volume than newly diagnosed gout patients. Regarding lower limb damage, $90 \%$ of first joint damage in patients with gout occurred in a single joint [20]. MSU crystal deposition can be seen inside and surrounding the joint in Figure 3.

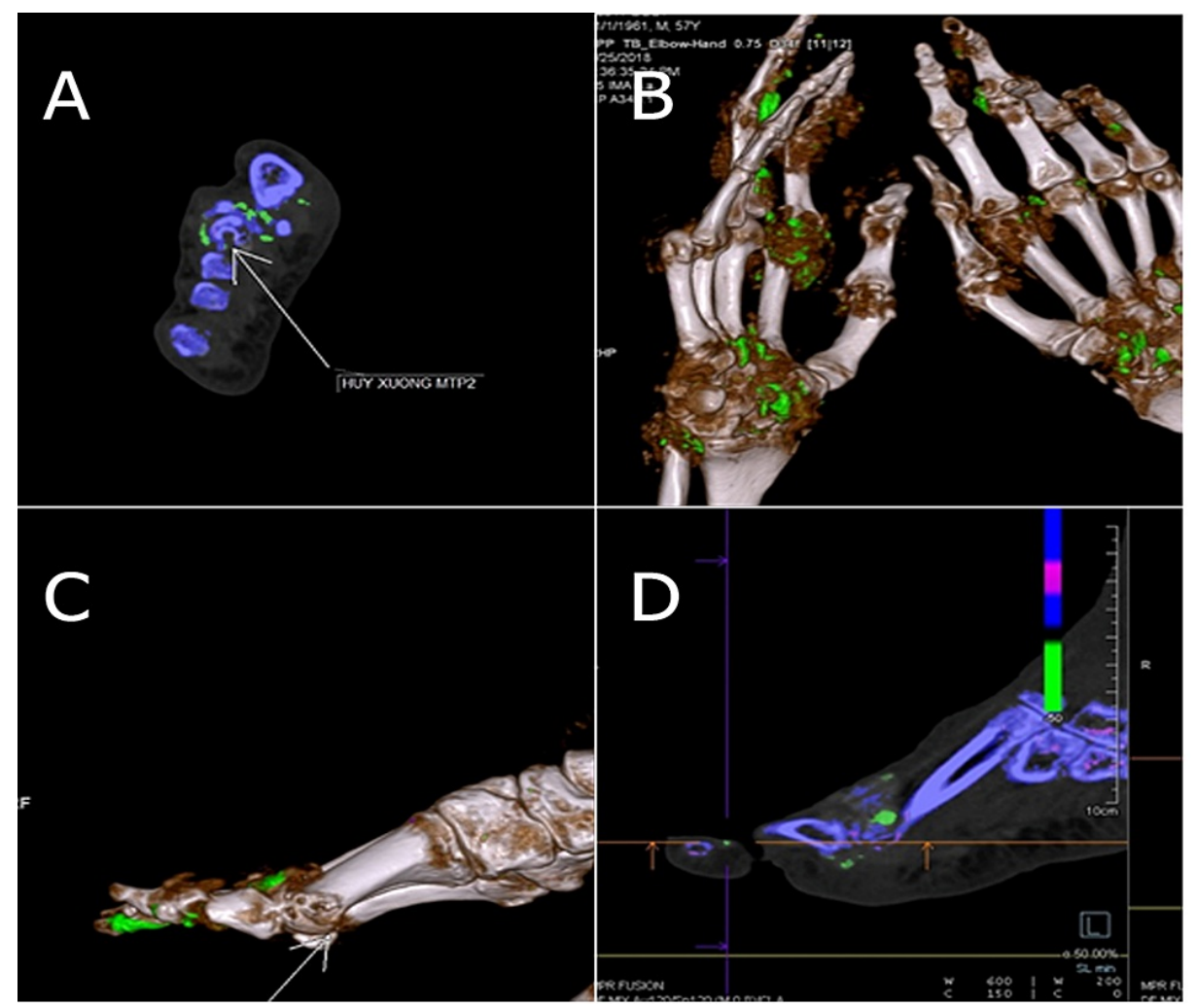

\section{FIGURE 3: MSU crystal deposition and periarticular calcification.}

A 67-year-old male was diagnosed with gout and presented with hyperuricemia (10 mg/dL). DECT images illustrated the sites of MSU crystal deposition; green color for MSU inside and outside of joints, and blue for periarticular calcification.

DECT: dual-energy computed tomography

Gout most commonly affects the MTP joint, as shown by clinical trials and imaging studies [21,22]. While all joints can be affected, lower limb joints are more often damaged than upper limb joints [21]. In our study, MSU crystals were detected in $48 \%(n=179 / 368)$ of the areas in the lower limb, almost twice of those detected in the upper limb at $25.5 \%(n=94 / 368)$.

In previous studies, MSU crystals were often found in the tendons of patients with chronic gout [23]. In knee joints, the meniscus is prone to MSU crystals; in the ankle, it is the body and root of the Achilles tendon; in the foot, it is the first MTP joint. In this study, 56.5\% ( $\mathrm{n}=104 / 184)$ of the joints had MSU crystal deposition, predominantly in the ankle. In the upper limb, the MCP2 was the most commonly affected, while MCP4 was the least affected. In this study, 33.9\% ( $n=78 / 230$ ) of the MTP joints had MSU crystal deposition. In the lower limb, MTP1 was the most commonly affected, while MTP5 was the least affected, which is in accordance with the study by Dalbeth et al. [14]. There are several hypotheses to explain why MTP1 is the 


\section{Cureus}

most commonly affected joint. When the big toe is bent toward other toes, the joint is bumped (bunion or hallux valgus). Gravitational force, when standing or walking, is exerted on the joints, causing pain. This joint deformity can also result from a weak foot structure due to genetics or other joint inflammatory conditions. In a recent study, the prevalence of bunion or hallux valgus was $41 \%$ in patients with gout compared to $25 \%$ in the control group [24]. MTP1 joint is the most prone to physical force and is located far away from the body at a low temperature. These are ideal conditions for MSU crystals to develop. In the upper limb, the triceps tendon was the most affected, which is consistent with the findings of Mallinson et al. In our study, the most affected areas with MSU were interracial, triceps tendon, and olecranon bursa, whereas in another study conducted by Mallinson et al., triceps tendon, hand tendons, and interracial tendons were the most affected regions [13]. In this study, 34.2\% ( $n=64 / 184)$ had MSU crystal deposition, predominantly in the elbow. MCP and MTP damage was also seen in joints with MSU crystal deposition (Figure 4). Overall, damage in the upper limb was less common than that in the lower limb.
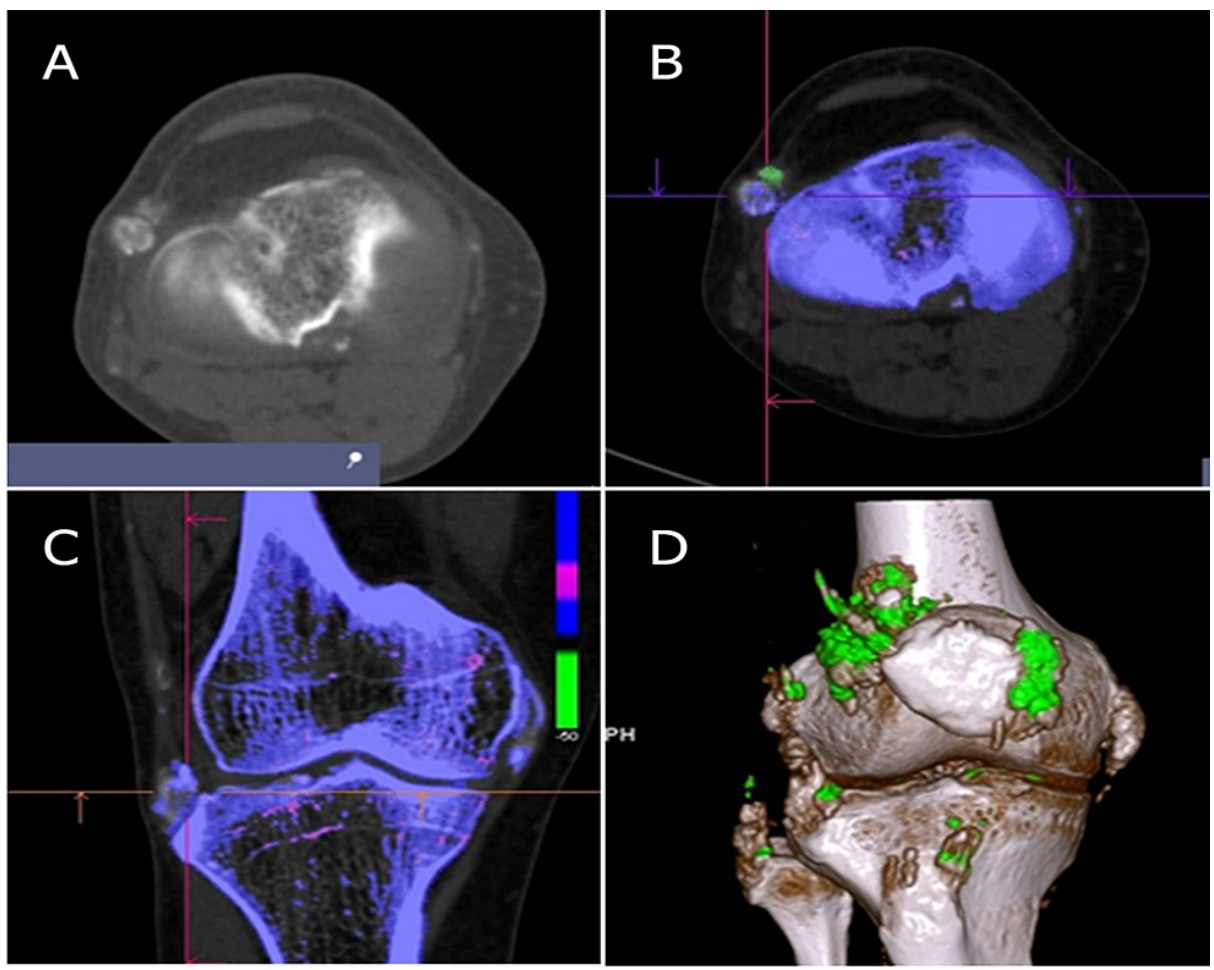

FIGURE 4: Structural damage in joints with MSU crystal deposition.

A 57-year-old male was diagnosed with gout and presented with hyperuricemia. Urate is shown in green color. Bone erosion is shown at right MTP2 (crystal volume $V=1.53 \mathrm{~cm}^{3}$ ) (A) and periarticular calcification is shown at left MTP1 (D). DECT 3D images also illustrated deformities at right MCP5 (crystal volume $V=0.01 \mathrm{~cm}^{3}$ ) and right MTP1 (crystal volume V $\left.=0.97 \mathrm{~cm}^{3}\right)(B$ and $C$ ).

DECT: dual-energy computed tomography; MSU: monosodium urate; 3D: three-dimensional; MTP: metatarsophalangeal; MCP: metacarpophalangeal

Our study is constrained by the small sample size. Moreover, the nature of cross-sectional investigations did not allow us to follow the progression of the disease. Furthermore, DECT has not been compared to other modern communication technologies. Further longitudinal studies with bigger sample sizes are required to better understand the natural history of the disease, the repercussions of the disease, and to compare the disease with other diagnostic modalities.

\section{Conclusions}

Our study demonstrated DECT as a reliable tool to detect MSU deposits, which aided in the diagnosis of gout in a Vietnamese population. Therefore, we recommend DECT scans for patients with suspected gout and unclear clinical presentation, as well as to monitor short-term and long-term outcomes after treatment. Further prospective studies with a larger sample size are needed to evaluate the effectiveness of this diagnostic method. Moreover, our results suggest the potential benefit of urate-lowering therapy for the treatment of structural joint damage.

\section{Additional Information}




\section{Disclosures}

Human subjects: Consent was obtained or waived by all participants in this study. Ethics Research Council of University of Medicine and Pharmacy at Ho Chi Minh City, Vietnam issued approval 402/DHYD-HD. Animal subjects: All authors have confirmed that this study did not involve animal subjects or tissue. Conflicts of interest: In compliance with the ICMJE uniform disclosure form, all authors declare the following: Payment/services info: All authors have declared that no financial support was received from any organization for the submitted work. Financial relationships: All authors have declared that they have no financial relationships at present or within the previous three years with any organizations that might have an interest in the submitted work. Other relationships: All authors have declared that there are no other relationships or activities that could appear to have influenced the submitted work.

\section{References}

1. Kuo CF, Grainge MJ, Mallen C, Zhang W, Doherty M: Comorbidities in patients with gout prior to and following diagnosis: case-control study. Ann Rheum Dis. 2016, 75:210-7. 10.1136/annrheumdis-2014-206410

2. Edwards NL: Gout. Primer on the Rheumatic Diseases. Klippel JH, Stone JH, Crofford LJ, White PH (ed): Springer, New York, NY; 2008. 241-62.

3. Wallace SL, Robinson H, Masi AT, Decker JL, McCarty DJ, Yü TF: Preliminary criteria for the classification of the acute arthritis of primary gout. Arthritis Rheum. 1977, 20:895-900. 10.1002/art.1780200320

4. Schlesinger N: Diagnosis of gout: clinical, laboratory, and radiologic findings . Am J Manag Care. 2005, 11:S443-50; quiz S465-8.

5. Chowalloor PV, Siew TK, Keen HI: Imaging in gout: a review of the recent developments . Ther Adv Musculoskelet Dis. 2014, 6:131-43. 10.1177/1759720X14542960

6. Akbarnia H, Zahn E: Knee arthrocentesis. StatPearls Publishing, Treasure Island, FL; 2021.

7. Choi HK, Al-Arfaj AM, Eftekhari A, Munk PL, Shojania K, Reid G, Nicolaou S: Dual energy computed tomography in tophaceous gout. Ann Rheum Dis. 2009, 68:1609-12. 10.1136/ard.2008.099713

8. Johnson RJ, Nakagawa T, Jalal D, Sánchez-Lozada LG, Kang DH, Ritz E: Uric acid and chronic kidney disease: which is chasing which?. Nephrol Dial Transplant. 2013, 28:2221-8. 10.1093/ndt/gft029

9. Kleber ME, Delgado G, Grammer TB, et al.: Uric acid and cardiovascular events: a Mendelian randomization study. J Am Soc Nephrol. 2015, 26:2831-8. 10.1681/ASN.2014070660

10. Ogdie A, Taylor WJ, Weatherall M, et al.: Imaging modalities for the classification of gout: systematic literature review and meta-analysis. Ann Rheum Dis. 2015, 74:1868-74. 10.1136/annrheumdis-2014-205431

11. Terkeltaub R: Gout. Epidemiology, pathology, and pathogenesis. Primer on the Rheumatic Diseases. Klippel JH (ed): Arthritis Foundation, Atlanta, GA; 2001. 312.

12. Choi HK, Burns LC, Shojania K, et al.: Dual energy CT in gout: a prospective validation study . Ann Rheum Dis. 2012, 71:1466-71. 10.1136/annrheumdis-2011-200976

13. Mallinson PI, Reagan AC, Coupal T, Munk PL, Ouellette H, Nicolaou S: The distribution of urate deposition within the extremities in gout: a review of 148 dual-energy CT cases. Skeletal Radiol. 2014, 43:277-81. 10.1007/s00256-013-1771-8

14. Dalbeth N, House ME, Aati O, et al.: Urate crystal deposition in asymptomatic hyperuricaemia and symptomatic gout: a dual energy CT study. Ann Rheum Dis. 2015, 74:908-11. 10.1136/annrheumdis-2014206397

15. Singh JA, Reddy SG, Kundukulam J: Risk factors for gout and prevention: a systematic review of the literature. Curr Opin Rheumatol. 2011, 23:192-202. 10.1097/BOR.0b013e3283438e13

16. Schlesinger N, Norquist JM, Watson DJ: Serum urate during acute gout. J Rheumatol. 2009, 36:1287-9. 10.3899/jrheum.080938

17. Dalbeth N, Phipps-Green A, Frampton C, Neogi T, Taylor WJ, Merriman TR: Relationship between serum urate concentration and clinically evident incident gout: an individual participant data analysis. Ann Rheum Dis. 2018, 77:1048-52. 10.1136/annrheumdis-2017-212288

18. Zhang W, Doherty M, Bardin T, et al.: EULAR evidence based recommendations for gout. Part II: management. Report of a task force of the EULAR Standing Committee for International Clinical Studies Including Therapeutics (ESCISIT). Ann Rheum Dis. 2006, 65:1312-24. 10.1136/ard.2006.055269

19. Khanna D, Fitzgerald JD, Khanna PP, et al.: 2012 American College of Rheumatology guidelines for management of gout. Part 1: systematic nonpharmacologic and pharmacologic therapeutic approaches to hyperuricemia. Arthritis Care Res (Hoboken). 2012, 64:1431-46. 10.1002/acr.21772

20. Kim KY, Ralph Schumacher H, Hunsche E, Wertheimer AI, Kong SX: A literature review of the epidemiology and treatment of acute gout. Clin Ther. 2003, 25:1593-617. 10.1016/s0149-2918(03)80158-3

21. Dhanda S, Jagmohan P, Quek ST: A re-look at an old disease: a multimodality review on gout . Clin Radiol. 2011, 66:984-92. 10.1016/j.crad.2011.04.011

22. Roddy E: Revisiting the pathogenesis of podagra: why does gout target the foot? . J Foot Ankle Res. 2011, 4:13. 10.1186/1757-1146-4-13

23. Dalbeth N, Kalluru R, Aati O, Horne A, Doyle AJ, McQueen FM: Tendon involvement in the feet of patients with gout: a dual-energy CT study. Ann Rheum Dis. 2013, 72:1545-8. 10.1136/annrheumdis-2012-202786

24. Roddy E, Zhang W, Doherty M: Gout and nodal osteoarthritis: a case-control study . Rheumatology (Oxford). 2008, 47:732-3. 10.1093/rheumatology/ken087 